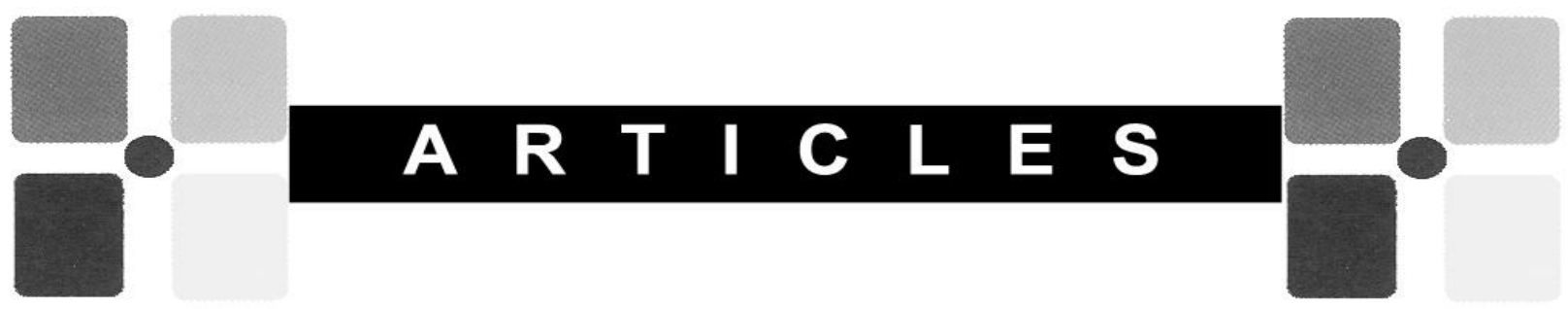

\title{
Intercultural Leadership Toolkit for Librarians: Building Awareness to Effectively Serve Diverse Multicultural Populations
}

\author{
By Dr. Suzie Allard and Dr. Bharat Mehra, University of Tennessee \\ And Dr. M. Asim Qayyum, University of Puerto Rico, Rio Piedras
}

\begin{abstract}
This paper presents five tools for librarians to use in building effective intercultural communication that reaches out to diverse populations. Librarians can more successfully cross intercultural boundaries if they are aware of the key tenets of intercultural communication and information provision, and then apply the five leadership tools in extending traditional information creation-organization-dissemination processes. The five tools are derived from an extensive literature review and from findings from seminar discussions with library and information science students.
\end{abstract}

\section{Introduction}

Populations that education librarians serve are becoming more diverse and frequently multilingual. This creates new challenges since a librarian must understand these diverse communities adequately in order to find ways to identify community and user needs and interests, and also to provide the collections and services to adequately meet these needs and interests.

One example of the growing diversity in the U.S. population is the increase in Latinos ${ }^{1}$. When the US population reached 200 million in the mid to late 1960s, Latinos accounted for $4 \%$ of the population. In 2006, the US population grew to 300 million, and Latinos accounted for $36 \%$ of the additional 100 million people (Pew, 2006). Latinos now account for about $15 \%$ of the US population (Pew, 2006). At the same time, there is also a significant growth in other cultures. For example, it is estimated that in California alone, there was a $127 \%$ increase in the Asian population during the period of 1980-1990 (Waters, 1992). This increasingly diverse population has changed many aspects of the community. For example, between the 1993/1994 and 2002/1003 school years, Latinos accounted for $64 \%$ of the students added to public school enrollment (Fry, 2006). Additionally, the rate of growth in the Latino labor force exceeds any other group (Kochhar, 2005).

This rapid change in demographics affects not only the community at large but the workplace and schools at all levels. It offers new challenges for librarians in special, academic, public and school libraries who are likely working with patrons who have a very different background than their own. Substantial implications may ensue since librarians might not recognize that societal structure is a nearly invisible part of daily life and that information structure is deeply embedded in a specific cultural contexts (Foucault, 1982, 2002). The Latino population offers a cogent example of how likely it is for a patron from a diverse community to be working with a librarian from a different cultural background. Currently there is one Latino librarian for every 9177 Latinos as compared to one Anglo librarian for every 1830 Anglos (Espinal, 
2003). Hiring more Latino librarians is not a feasible short-term solution, since between 1995 and 2000 only $3.1 \%$ of all MLS graduates were Latino and the number seems to be declining (Espinal, 2003).

This suggests that Latino patrons are often working with non-Latino librarians; therefore, it is imperative for non-Latino librarians to have an ability to cross cultural boundaries in order to provide responsive information services. The Latino population is one example; however, the challenges of crossing cultural boundaries also applies to reaching out to other diverse groups.

Librarians will be more successful in crossing this boundary if they recognize key tenets of intercultural communication and the implications for information provision. This paper builds awareness by providing librarians with five tools that can instantly be put to use. These tools help a librarian more readily respond to the needs of the community by understanding the community's culture in terms of the beliefs people hold about the world, the values they share about living in the community, and the way they treat one another (Bennett, 1998). With this awareness, the librarian can adjust for cultural differences that might influence the collection, management and provision of information. The paper also discusses implications for the profession based on the literature and the findings from a symposium which was conducted to explore the issue.

\section{Building Awareness: Identifying and Understanding Cultural Differences of Diverse Populations}

Culture is one influential characteristic of a diverse population. Cultural differences can make it more difficult for people to communicate clearly. Misunderstanding or misinterpreting verbal and nonverbal cues can cause confusion, leading to anxiety and tensions among coworkers and in librarian-client relationships. Librarians need to learn communication techniques that honor different cultural perspectives. Culture may be understood from three main perspectives.

1. "Objective culture" refers to the history and facts about a culture, including the language the culture uses (Bennett,1998). Being familiar with objective culture allows one to know the facts about a culture but it does not necessarily help an individual successfully interact with another culture.

2. "Subjective culture" refers to the beliefs that people hold about the world, the values they share about living in the community, and the way they treat one another (Bennett,1998). Successful communication requires an understanding of subjective culture. Culture may be learned through the media, through stories, through music, and through spiritual teachings; however, it is primarily passed from one generation to the next (Bates \& Plog, 1990). This "handing down" of culture makes it more difficult for librarians to gain an understanding of another group's culture. Therefore, librarians must begin to build intercultural competence by understanding their own subjective culture and by recognizing the subjective culture of others.

3. The third interpretation of culture recognizes its characteristics as a "lived experience" (Mehra and Papajohn 2007). Culture is enacted as an ever-changing and hybridized phenomena (Appadurai, 1990) that impacts individual lives "in ongoing interaction" (Apple \& Weis, 1983, 15-16) with the situational context and the external social and political environment (Bhabha, 1994). This perspective promotes successful interaction with diverse multicultural populations, and extends the interaction into collaborative partnering (Mehra and Bishop, 2007) by recognizing the underlying power imbalances embedded in people's experiences and taking action that works with, instead of "for," diverse populations (Mehra, 2006). This reality implies that librarians must adopt a more participative model that values the experiences, knowledge base, and role of diverse underserved populations in the processes of knowledge/information creationorganization-dissemination (Mehra, Albright, and Rioux, 2006).

Librarians need additional tools to increase their success of intercultural communication, "reaching out" to diverse and multicultural populations. The five tools in this paper were developed by creating a foundation from the multi-dimensional and dynamic concepts of culture noted above, and by using findings obtained from two three-hour seminar discussions with more than fifty library and information science students at the University of Tennessee and the University of Puerto Rico in October, 2006. 
Tool 1: Identify Cultural Dimension. One dimension of cultural variance is determining if the culture has an "individualistic" or "collectivistic" perspective (Hofstede, 1980). Individualistic cultures place a high value on the initiative of individuals and their achievements. In an individualistic culture people are expected to pursue their own dreams and fulfill their own potentials. Independence and individual achievement are highly valued. An individualistic culture's world view tends to reflect the idea that there are absolute facts about the world that are separate from the meaning for humankind. Most western societies are considered individualistic cultures, where individual activity is emphasized and personal competition is valued. Credit or blame, reward or punishment falls on the individual.

Collectivistic cultures place a high value on people identifying with, or belonging to, groups larger than a family unit. These groups provide support for their members, and the members share responsibility and accountability for the group's activities. The world view tends to be one in which the physical world is viewed in context of what it means for humankind. Most Asian and African societies and others in the Global South are regarded to be collectivistic cultures (Triandis, 1993). An example of a collectivistic culture is China, where collective efforts are emphasized, and personal goals and accomplishments are deemphasized (Zhang, 2002). Anecdotal evidence shows that the Latino culture follows similar trends. In such cultures, interdependence and success of the group is highly valued. Therefore, credit or blame, reward or punishment, falls on the group rather than on the individual.

Culture as lived experience recognizes the ongoing tensions faced by individuals from multicultural populations in the United States who must negotiate their collectivistic values, behaviors, and relationships while being embedded in the social, cultural, economic, and political environment of a culture that is individualistic (Niles, 1998; Mehra, 2004a). Identification of the cultural dimensions of coworkers and clients by information professionals can lower the cultural and communication barriers. For example, librarians may recognize how the individualistic-collectivistic conflicts faced by individuals are represented in their information-seeking behaviors, and can then provide information services that acknowledge these complex realities (Mehra, 2004b).

Tool 2: Identify Cultural Communication Style. Cultures vary in the way their members communicate. Cultures may have low-context or high-context communication (Hall, 1976). In low-context communication, information in a message is contained in the words of the message. Low-context communication tends to be direct, and requires people to speak openly about information to understand the society and the relationships. Low-context communication features messages that are highly structured and provide a high level of detail (Hall, 1976).

High-context communication relies on more than the words to impart information. Information is conveyed through the context of the communication, including how a person says something, and non-verbal clues such as culture specific mannerisms, which assumes that the communicators have a high degree of shared knowledge about the society (Hall, 1976). The messages are simple and do not have a high degree of detail. To someone who is not a member of the society, messages may seem simple and ambiguous since they do not have the context needed to understand them.

There is a tendency for individualistic cultures to have low-context communication, while collectivist cultures tend to participate in high-context communication. Although this is not always the case, it is essential that librarians develop a communication pattern at the workplace that is perceived as mutually acceptable and comfortable (Zhang, 2002). One suggested way of doing this is to avoid the use of any words or gestures that might cause misunderstandings or misinterpretations. Librarians should also hone their communication techniques of attentive listening, use of clear spoken and written language, and sensitivity of always keeping the communication channels open. If one mode of communications fails, they can use another one.

Culture as a lived experience allows reflection on both the symbolic and tangible context of the communication. It focuses on the power discourse of who is speaking to whom, what is being said, why and how the communication is taking place, and what is the over-all purpose of the interaction. This provides a tool to understand the cultural realities enacted as emergent processes where "new meanings, new practices, 
new significances and experiences are continually being created" (Williams, 1973, 11) from their points of view in the context of what is meaningful to the patron (Mehra, Merkel, and Bishop, 2004).

\section{Building Awareness: Working with Information and Diverse Populations}

Information structure is embedded in a cultural context; it is difficult to discern how social categories and practices originated and the consequences that have resulted for the use, storage and dissemination of information (Foucault, 1982, 2002). Nevertheless, lack of access and use of information systems and services by cultural groups influence socioeconomic and sociopolitical inequalities for the have-nots (Mehra, Bishop, Bazzell, and Smith, 2002). This actuality suggests that libraries should be involved in local communities, including initiatives that make a real difference in everyday lives of underserved populations (Mehra, 2005). This perspective leads to the development of three more tools that librarians can utilize when they are working in tasks related to information management or information provision.

Tool 3: Recognize Who and What Might be Marginalized. Because information structure reflects the beliefs and values of a culture, information related to certain segments of a population within a diverse society may be marginalized or overlooked. The majority community may not do this intentionally, but rather out of ignorance about the diversity of cultures existing within the society or a lack of feeling the need to do anything. Therefore, the minority group must make an effort to reach out to the majority community. Only through this interaction can they ensure the availability of their cultural information to the dominant community. A librarian can facilitate this by maintaining an awareness of the community members and providing an environment that is approachable.

Culture as lived experience allows the librarian to question the dominant hegemonic forces that shape information creation-organization-dissemination processes. Librarians can recognize the gaps that exist in the provision of information services: who is left out in the processes of information delivery, and how efforts should be made to "open up" the information structure to make it more encompassing and inclusive in its ordering, content, management, and membership (Bishop, Mehra, Bazzell, and Smith, 2003). Libraries can play an important role in building awareness about the diversity of cultures existing within the community. Librarians can contribute to this community-building effort by maintaining open channels of communications, by developing collections that cater to the needs of their marginalized clients, and by recognizing the marginalized information and help in its dissemination.. Dissemination can occur through lectures and visits by cultural representatives, or by holding story telling or poster sessions that exemplify information about minority communities.

Tool 4: Recognize Mechanisms for Organizing and Supplying Information. Groups that have the ability to name and manipulate the information structure are likely to have a stronger presence in the society. Consequently, dominant cultural groups naturally tend to dominate the information structures. Many scholars agree that classification systems are culturally built institutions and as such, they can marginalize cultures who are not adequately represented in the classification scheme (Olson, 1998). Classification systems reflect the culture in which they were created in terms of philosophical assumptions and ideological presumptions. For example, Sukiasian (cited in Olson, 1998) studied how the Soviet classification system needed to be reconstructed after the break-up of the Soviet Union since information about the now- independent former Soviet republics needed to be included and organized. Another example involves the Dewey Decimal Classification System, which was conceived in the U.S. This system has a separate section for American (U.S.) literature while all other literature is arranged by language regardless of the country of origin (Olson, 1998). Exploring culture as a lived experience provides intellectual and actualized ways to represent local knowledge, ontologies, conceptualizations, and experiences of diverse multicultural populations. These representations can be incorporated into mainstream library systems and classification by facilitating active participation from individuals from these marginalized communities (Mehra and Srinivasan, under review).

Tool 5: Recognize Who Built the Information Technology. Information technologies are constructed by people living within a culture; therefore, the technology is likely to reflect the creator's cultural viewpoint. Some assumptions are made naturally when building most technologies, such as the fact that peo- 
ple have five fingers on each hand and that they will be able to see. However, just as an individual might not consider that someone may have lost a finger or lost their sight, librarians might not consider design features that are culturally bound such as date conventions or holiday observances. As an example in the use of digital libraries across cultures, Bilal and Bachir (2007) studied the use of International Children Digital Library (ICDL) by Arab children. A major conclusion was that the older children, perhaps because of their lengthier exposure to the western world's computer symbolism, understood the navigational representations much better than the younger children. It can safely be assumed that most immigrants, especially the older ones, who settle in a new and different culture would face similar constraints.

Culture as lived experience allows librarians to consider how different social groups use technologies, and how they may change and adapt them to be used in ways that were not conceived of in the initial design. Additionally, emergent cultures realize some features to consider when designing technologies such as the language of the culture (and its embedded power interplay) and how that may be represented more equitably by new technologies. For example, in the early days of computers only Roman characters were recognized by computer applications. However, over time computer scientists have added many character sets prevalent in non-European languages and found ways to provide powerful tools such as search capabilities across these different symbols.

\section{Diverse Populations and the Profession}

The five tools noted above can immediately be employed by individual librarians in their daily work. However, the profession does recognize the growing need to reach out to diverse populations, which suggests that a systematic program to foster intercultural leadership is needed. Literature suggests that although leadership did not appear as a desired skill for librarians until the early 1990s, there is now a growing lack of leadership while there is increasing diversity and minority participation in the profession (Mason \&. Weatherbee, 2004). On the other hand, once a member of the minority group does make it to the top, questions are often raised regarding his or her competency, especially if the leader happens to be an African-American or a Latino (Zhang, 2002). The two trends show that a need exists to train all librarians in intercultural relationships, regardless of whether they hail from a majority group or a minority group. In answer to this need, the authors are creating developing a bilingual Intercultural Leadership Toolkit, which will provide integrated training and resource modules to support librarians' intercultural leadership competencies that will help them better serve their communities and support an intercultural workplace.

The need for the Toolkit is further bolstered by the fact that there is a demand for leadership training. In a 2001 survey, $40 \%$ of the respondents had taken leadership and career training, and wanted additional leadership training (ETI, 2001). While library leadership is beginning to be addressed, there is not a focus on intercultural leadership in the information professions even though diversity is increasing. For example, while there are at least ten library leadership programs available in Florida through professional associations (Kear, 2005) they are not specifically geared towards intercultural leadership even though the state has great diversity. Intercultural leadership requires special attention since, as Peng (2006) notes, intercultural consciousness in leadership is a "synergistic combination of essential cognitive, emotional and behavioral knowledge and skills for intercultural competence and a commitment to consistent caring and ethical application of those skills and knowledge" (38).

In order to better understand the situation, the authors conducted the "Intercultural Leadership Toolkit Symposium" in October 2006 at the University of Tennessee (UT). The symposium featured events at both UT and the University of Puerto Rico, and included brainstorming workshops and seminar discussions with practitioners, academics, and students. Some events were linked electronically through the use of streaming video and Blackboard courseware. It was learned that library and information science graduate students do not have a solid background in intercultural issues, and students and practitioners feel leadership in this area is an important skill for the $21^{\text {st }}$ century information professional. Below are select findings from symposium activities conducted during a three-hour seminar discussion with more than fifty library and information science graduate students at UT and UPR. 


\section{Defining Intercultural Leadership}

Intercultural leadership is defined here as the knowledge and clear vision to successfully negotiate relationships with people from other cultures and from different linguistic traditions. For example, a librarian who has intercultural leadership skills may be a guide to others in his or her own library or the profession by taking actions that facilitate information provision to a diverse intercultural community. Three core areas of intercultural leadership emerged from the symposium: 1) leadership; 2) diversity and democracy; and 3 ) information and communication processes. Based on findings from the Intercultural Leadership Toolkit Symposium, the core areas are described as follows.

Leadership addresses different styles and theories of leadership, and how they relate to information and communication in an intercultural environment. It focuses on the role of the librarian or information professional as a leader. Special attention is paid to leadership at different levels (e.g., it is important to understand the differences of being a leader in a small informal group versus being a leader in a large organizational setting).

Diversity and democracy addresses the definitions and concepts associated with the terms intercultural, multicultural, diversity and democracy. It provides a foundation for people to better understand the issues related to these concepts and to how leadership plays a role. It focuses on how these issues relate to librarians and information professionals in the $21^{\text {st }}$ century.

Information and communication processes explore the role of culture in the way people save, use and communicate information and in how they communicate with each other. It provides a foundation for librarians and information professionals to understand that cultural practices may be embedded in many activities that take place in the library and information agency. It focuses on how librarians and information professionals in the $21^{\text {st }}$ century can provide leadership in information transactions so that intercultural issues can be recognized and addressed.

\section{Skills for Intercultural Leadership in the Information Professions}

Interesting insights can be drawn from the results of the three-hour seminar discussions with professionals-in-training participants. Based on the information gathered in these discussions, the authors identified key areas that the profession must address to facilitate librarians becoming intercultural leaders who can extend traditional information creation-organization-dissemination processes to effectively serve diverse multicultural populations residing in local and regional communities. A librarian who can serve as an intercultural leader must have the knowledge, skills, and institutional support to carry out the following actions.

- Critically reflect upon existing information gathering, organizing, and accessing strategies to insure that minority voices other than the majority are represented in these processes.

- Expand existing library collections to prevent cultural bias and incorporate items published by alternative presses and non-mainstream publication houses (these include Spanish and bilingual materials).

- Provide visible locations and proactively advertise and market existence of non-traditional items in the library collections.

- Distribute allocations and manage finances in an equitable and fair manner that provides access to diverse multicultural collections, services, programs, and events.

- Go beyond patron recommendations, customer needs, and popular readings to represent multicultural materials in the library collections.

- Provide "on the job" training and a range of experiences to practicum students and new staff in working with multicultural populations.

- Consider all forms of diversity based on race, ethnicity, gender, sex, sexual orientation, age, disabilities, income, geography, skills, religion, national origins, and others while evaluating the library as a place to represent the needs of all kinds of people.

- Partner with local community-based groups, agencies, and individuals to assess and evaluate library services. 
- Make multicultural populations feel welcome to the library by providing specific workshops, training, and events for their participation.

- Conduct regular needs assessment surveys to include minority and traditionally underserved populations.

- Conduct assessment of local, regional, and national libraries and information centers to identify effective services and programs these institutions are offering to multicultural populations.

- Refrain from personal judgment and bias towards information and experiences similar to your own.

- Cultivate listening skills, and be empathetic towards experiences of people different from yourself.

\section{Conclusion}

The library profession is facing new challenges in information services in order to reach out to the increasingly diverse, and often multilingual, populations it is serving. Education librarians working with diverse populations can immediately address the challenges by utilizing the five tools noted in this article: identifying cultural dimension, identifying cultural communication style, recognizing who and what might be marginalized, recognizing mechanisms for organizing and supplying information, and recognizing who built the information technology.

However, the profession would be well-served by focusing on offering librarians the opportunity to develop strong intercultural leadership skills. If librarians become intercultural leaders, they will be able to successfully negotiate relationships with and better serve their patrons from other cultures and linguistic traditions. The authors have begun developing an Intercultural Leadership Toolkit which will provide librarians with tools to better understand and utilize skills related to leadership, diversity and democracy, and information and communication processes.

\section{Footnote}

1. Although the U.S. Census uses the term Hispanic, most individuals self-select the term Latino to describe themselves; therefore, Latino is the term used in this article.

\section{References}

Appadurai, A. 1996. Modernity at large: Cultural dimensions of globalization. Minneapolis, MN: University of Minnesota Press.

Apple, M. W., \& Weis, L. (Eds.). (1983). Ideology and practice in schooling. Philadelphia: Temple University Press.

Bates, D., \& Plog, F. (1990). Cultural anthropology. New York: McGraw-Hill.

Bennett, M. (1998). Basic concepts of intercultural communication. Yarmouth, ME: Intercultural Press.

Bhabha, H. K. (1994). The location of culture. New York: Routledge.

Bilal, D. \& Bachir, I. (2007). Children's interaction with cross-cultural and multilingual digital libraries: I. Understanding interface design representations. Information Processing and Management. 43(1), 47-64.

Bishop, A. P., Mehra, B., Bazzell, I., \& Smith, C. (2003). Participatory action research and digital libraries: Reframing evaluation. In: A. P. Bishop, N. Van House, and B.Buttenfield (Eds.), Digital library use: Social practice in design and evaluation. Cambridge, MA: MIT Press.

Espinal, I. (2003). Wanted: Latino librarians. Criticas, 3(5), 19-24.

Evaluation and Training Institute (ETI) (2001). California library staff continuing education needs assessment. Unpublished report in Mason, F. M. \&. Wetherbee, L. V. (2004). Learning to lead: An analysis of current training programs for library leadership. Library Trends, 53(1), 187-217.

Foucault, M. (1982). The archaeology of knowledge \& the discourse on language. New York: Pantheon. Foucault, M. (2002). The order of things: An archaeology of the human sciences. London: Routledge.

Fry, R. (2006) The changing landscape of American public education: new students, new schools. Pew Hispanic Center. Retrieved November 20, 2006, from http://pewhispanic.org/reports/report.php? ReportID=72.

Hall, E.T. (1976). Beyond culture. New York: Doubleday.

Hofstede, G. H. (1980). Culture's consequences: International differences in work-related values. Thousand Oaks, CA: Sage Publications. 
Kear, R. (2005). Learning to be a library leader: Leadership development opportunities in Florida and beyond. Florida Libraries, 48(2), 22-23.

Kochhar, R. (2005) The occupational status and mobility of Hispanics. Pew Hispanic Center. Retrieved November 20, 2006, from http://pewhispanic.org/reports/report.php?ReportlD=59.

Mason, F. M., \&. Wetherbee, L. V. (2004). Learning to lead: An analysis of current training programs for library leadership. Library Trends, 53(1), 187-217.

Mehra, B. (2004a). The cross-cultural learning process of international doctoral students: A case study in library and information science education. Unpublished dissertation. University of Illinois at Urbana-Champaign.

Mehra, B. (2004b). Service learning in library and information science (LIS) education: Connecting research and practice to community. InterActions: UCLA Journal of Information and Education Studies, 1(1), Article 3.

Mehra, B. (2005). Library and information science (LIS) and community development: Use of information and communication technology (ICT) to support a social equity agenda. Journal of the Community Development Society, 36(1), 28-40.

Mehra, B. (2006). An action research (AR) manifesto for cyberculture power to "marginalized" cultures of difference. In: D. Silver, \& A. Massanari (Eds.), Critical cyber-culture studies (pp. 205-215). New York: New York University Press.

Mehra, B., Albright, K. S., \& Rioux, K. (2006). A practical framework for social justice research in the information professions. Proceedings of the $69^{\text {th }}$ Annual Meeting of the American Society for Information Science \& Technology 2006: Information Realities: Shaping the Digital Future For All.

Mehra, B., \& Bishop, A. P. (2007). Cross-cultural perspectives of international doctoral students: "twoway" learning in library and information science education. International Journal of Progressive Education, 3(1). Retrieved April 20, 2007, from http://www.inased.org/v3n1/mehrabishop.htm.

Mehra, B., Bishop, A. P., Bazzell, I., \& Smith, C. (2002). Scenarios in the Afya Project as a participatory action research (par) tool for studying information seeking and use across the "digital divide". Journal of the American Society of Information Science and Technology, 53(14), 1259-1266.

Mehra, B., Merkel, C., \& Bishop, A. P. (2004). Internet for empowerment of minority and marginalized communities. New Media \& Society, 6(5), 781-802.

Mehra, B., \& Papajohn, D. (2007). "Global" patterns of communication-information convergences in internet use: cross-cultural behavior of international teaching assistants in a culturally alien information environment. The International Information \& Library Review, 39(1),12-30.

Mehra, B., \& Srinivasan, R. (under review). The library-community convergence framework for community action: a new role of the library as a catalyst of social change. Libri: International Journal of Libraries and Information Services.

Niles, F. S. (1998). Individualism-collectivism revisited. Cross-Cultural Research, 32(4), 315-341.

Olson, H. (1998). Mapping beyond Dewey's boundaries: Constructing classificatory space for marginalized knowledge domains. Library Trends, 47, 233-254.

Peng, Shi-Yong. (2006). A comparative perspective of intercultural sensitivity between college students and multinational employees in China. Multicultural Perspectives, 8(3), 38-45.

Pew Hispanic Center. (2006) The Mission of the Pew Hispanic Center: Chronicling Latinos' diverse experiences in a changing America. Washington, DC: Author. Retrieved April 20, 2007, from http://pewhispanic.org/about/.

Triandis, H. C. (1993). Collectivism and individualism as central syndromes. Cross-Cultural Research, 27(3-4), 155-180.

Waters, H., Jr. (1992). Minority leadership problems. Journal of Education for Business, 68(1), 15-20.

Williams, R. (1973). A base and superstructure in Marxist cultural theory. @ New Left Review 82, 3-16.

Zhang, X. (2002). Library minority managers: Ways to survive and to succeed. Journal of Educational Media \& Library Sciences. 39(3), 227-34.

Dr. Suzie Allard is an Assistant Professor within the School of Information Sciences at the University of Tennessee. Email: sallard@utk.edu

Dr. Bharat Mehra is an Assistant Professor within the School of Information Sciences at University of Tennessee. Email: bmehra@utk.edu

Dr. M. Asim Qayyum is an Assistant Professor within the Escuela Graduada de Ciencias Y Tecnologías de la Información (EGCTI) at the University of Puerto Rico in Rio Piedras. Email: qayyum@uprrp.edu 